\title{
A Qualitative In-depth Analysis of the Determinants and Outcomes of EFL Teachers' Motivation and Demotivation
}

\section{Zahra Pourtoussi}

Imam Reza International University, Mashhad, Iran

\section{Afsaneh Ghanizadeh}

Imam Reza International University, Mashhad, Iran,a.ghanizadeh@imamreza.ac.ir

Vahid Mousavi

Imam Reza International University, Mashhad, Iran

The current study probed qualitatively the antecedents and consequences of teachers' motivation and demotivation among Iranian English as foreign language (EFL) teachers. To conduct the study, four different kinds of qualitative methods were triangulated, including interviews, diaries, journal, and open-ended questions. To analyze the obtained data, MAXQDA 10 software was used offering the researchers a wide variety of visual tools, diagrams, and tables. The results demonstrated that the antecedents encompassed two broad factors (job-related factors and immediate environment) and a number of sub-factors. Besides, the consequences have three main categories (physical, behavioural, and attitudinal) and a host of sub categories. All in all, the results demonstrated that most of the antecedents and consequences were external rather than internal; so, it is recommended that teaching environment should be enhanced both physically and professionally in order to promote teacher motivation conducive to learner motivation and effective learning.

Keywords: consequences, demotivation, determinants, EFL teachers, motivation

\section{INTRODUCTION}

It seems quite evident that motivation plays a prominent role in students' and teachers' lives. As Gardner (1985) contended motivation is the most influential and significant factor in L2 learning. Motivation pushes the teachers and students to their goals. On the contrary, demotivation is the opposite side of motivation which stops or diminishes their efforts. Motivation and its flip side, demotivation, has been the appealing topic for many scholars in L2 learning (Bernaus \& Gardner, 2008; Ghanizadeh \& Rostami, 2015; Ghonsooly, Hassanzadeh, Samavarchi, \& Hamedi, 2017; Jahedizadeh, Ghanizadeh, \& Ghonsooly, 2016; Meshkat \& Hassani, 2012).

Citation: Pourtoussi, Z., Ghanizadeh, A., \& Mousavi, V. (2018). A Qualitative In-depth Analysis of the Determinants and Outcomes of EFL Teachers' Motivation and Demotivation .International Journal of Instruction, 11(4), 175-190. https://doi.org/10.12973/iji.2018.11412a 
Some studies (e.g., Fernet et al., 2008; Royaei \& Ghanizadeh, 2016) indicated that teacher motivation can be studied from two social cognitive theories of motivation including self-efficacy (Bandura, 1977) and internal-external locus of control (Rotter, 1966).

Also, some scholars develop the idea that motivation embraces 3 types of motivation including intrinsic motivation, extrinsic motivation, and amotivation, which are characterized by different levels of SDT (self-determination theory) (Fernet, Senécal, Guay, Marsh, \& Dowson, 2008). These three types of regulation differ in the selfdetermination side from lower to higher levels of self-determination. While the first type of regulation refers to obtaining or avoiding an activity, the second type corresponds to internalizing an external demand. Finally, the last type refers to a particular concept meaning that the person is not motivated intrinsically or extrinsically (Vallerand, 1997).

Dörnyei (2005) reported when we view motivation as a dynamic, continuously evolving out of variety of internal and external forces, it leads to the internal monitoring, filtering, and processing mechanisms that learners utilize in this dynamic process. This process in turn will have an important role in shaping the motivational outcome.

In the domain of teaching, some factors can influence motivation including job dissatisfaction, stress, and burnout. These factors can affect motivation in a negative manner according to Sternberg and Dai (2004). In a research done by Fattash (2013), four demotivating factors were investigated among university teachers including extrinsic factors, student factors, administrative factors, and department factors.

The next issue which we discuss here is demotivation. As Dornyei (2001) defined, demotivation is "specific external force that reduces or diminishes the motivational basis of a behavioural intention or an ongoing action" (p. 143). Also, it is notable to mention that demotivation can also be both external and internal. A study in a foreign language context revealed that demotivated people do not have any sense of motivation in the task once they were interested in; therefore, these kind of people are not willing to follow the activities once they start them (Yan, 2009).

Moreover, another study indicated that educators can hardly have any control over demotivation because of its origin from attitudinal influence (Dörnyei \& Ushioda, 2011). Also some scholars indicated specific results of motivation or demotivation. Dörnyei (2005) reported that teacher motivation can influence student motivation and learning achievement; moreover, a healthy and productive learning environment for their students, work environment for their colleagues, and career for themselves is for teachers to keep motivation.

Teachers seek for autonomy and a suitable situation to practice their competence in the classroom, but when they cannot reach such a goal, negative feelings can occur including devaluation and isolation leading to job dissatisfaction and demotivation (Falout, 2010). A recent qualitative study done by a Turkish researcher showed that demotivating factors in the English as a foreign language contexts are teaching profession, curriculum, conditions with regard to physical and working aspects, and nearly all the people who are involved in the teachers' everyday interaction including 
colleagues, students, administrators, and students' parents (Aydin, 2012). A similar study by Arai (2004) revealed that demotivating reasons for Japanese teachers were detected as four main categories including teachers' behaviour, monotonous classes, class atmospheres, and others.

\section{Purpose of the study}

Researchers have quite recently started to investigate teachers' motivation within Iranian context (Ghanizadeh \& Erfanian, 2017). Although learner motivation has been studied, less attention has been paid motivating and demotivating factors for teachers in a single study. The objective of this research is to elucidate the determinants and consequences of Iranian EFL teachers' motivation and demotivation qualitatively. As English teachers play a significant role in the life of the language learners and the potential future language users, English teachers' role may be one of the concerns of the educational system. Due to this reason, they are faced with various issues in language schools and institutes where huge numbers of teachers are recruited. While they are teaching English language in their classes; they encounter various intricacies such as dealing with versatile linguistic and cultural difficulties as well as different kinds of organizational behaviour that teachers experience including their motivation and demotivation which may not be considered.

The current research focused on different decisive factors and elements which shape EFL teachers' motivation and demotivation as well as the effects of EFL teachers' motivation and demotivation on different aspects of their performance. To do so, a qualitative research addressing the following research questions was designed:

1) What are the antecedents of EFL teachers' motivation?

2) What are the antecedents of EFL teachers' demotivation?

3) What are the consequences of EFL teachers' motivation?

4) What are the consequences of EFL teachers' demotivation?

\section{METHOD}

\section{Participants}

The study included 3 phases. In the first part of the research, 16 teachers were asked to complete two open-ended questions. In the second phase, 10 teachers who were Bachelor of Arts (B.A.) graduates or Master of Arts (M.A.) students of TEFL (Teaching English as a Foreign Language) at Imam Reza International University participated in the interview. In the third phase, the researcher kept writing her journal and 2 other teachers wrote their diaries while they taught English in the classes.

\section{Instrumentation}

Owing to the fact that this research had an exploratory nature, a triangulated qualitative method was applied in order to take the advantage of more valid findings which can cyclically check each other.

Open ended questions

Two open ended questions were designed and distributed among teachers in an English institute in Mashhad and online in telegram groups which is a social networking 
application. The members of the group were teachers from all over Iran especially Mashhad and Tehran. So 16 participants completed the open ended questions and wrote about the causes and consequences of their motivation and demotivation in their classes.

Interview

The interviews were designed by the researchers as semi-structured interviews and performed in single sessions. Each of them lasted about 15 minutes. Before the interview, the researcher made them familiar with the topic and some technical terms which could be used in the session.

The respondents of the interview asked to express their ideas, feelings, and emotions. Although they were assured about the confidentiality of the research, some of the teachers who completed the open ended questions ignored to participate in the interview. Nine teachers participated in the interview. The researcher recorded their voices, and sent them back to the participants for further elaboration and correction if needed. All the voices were recorded, transcribed, and finally translated into English. The interviews started on $29^{\text {th }}$ of October 2017 and ended on $23^{\text {rd }}$ of November 2017. Table 1 indicates the participants' background information.

Table1

Background Information of the Interviewees

\begin{tabular}{lllll}
\hline Number & Age & Gender & Years of experience & Degree \\
\hline 1 & 24 & Female & 4 & B.A. in TEFL \\
2 & 30 & Female & 4 & B.A. in TEFL \\
3 & 23 & Female & 3 & M.A.in TEFL \\
4 & 23 & Female & Roughly 1 & B.A. in TEFL \\
5 & 31 & Female & 5 & B.A. in TEFL \\
6 & 22 & Female & 3 & B.A. in TEFL \\
7 & 24 & Female & Roughly 1 & B.A. in TEFL \\
8 & 22 & Female & 3 & B.A. in TEFL \\
9 & 22 & Female & 2 & M.A.in TEFL \\
\hline
\end{tabular}

Diaries and Journal

The researcher asked two participants to write their professional diaries, and their reflecting ideas on motivating and demotivating factors they encountered in their class in intervals as two sessions in a week.

Two teachers wrote down what they felt, both motivation and demotivation cases while they taught during their classes. Also, the researcher kept writing her journal during various sessions. In Table 2, the information of the teachers who wrote their diaries is shown.

Table 2

Background Information of the Diary and Journal Participants

\begin{tabular}{lllll}
\hline Number & Age & Gender & Years of experience & degree \\
\hline 1 & 23 & Female & 3 & M.A. in TEFL \\
2 & 35 & Female & 14 & M.A. in Translation studies \\
3 & 22 & Female & 1.5 & M.A. in TEFL \\
\hline
\end{tabular}




\section{Data analysis}

For the analysis of this qualitative study, the researchers used MAXQDA 10 software which gave them wide opportunities to deeply analyze the factors and consequences of motivation and demotivation, and to draw and use several visual maps and classifications. The open ended questions, interviews, diaries and researcher's journal were all entered to the software, and were then coded and analyzed.

\section{FINDINGS}

\section{The model of Antecedents of Teachers' Motivation and Demotivation}

According to the codes which were gathered from 3 sources including interview, diaries, and open-ended questions, antecedents of motivation and demotivation were classified under two broad categories as 1) immediate setting and 2) job-related factors.

Each category is associated with a number of sub-factors. Figure 1 depicts the antecedents of EFL teachers' motivation and demotivation.

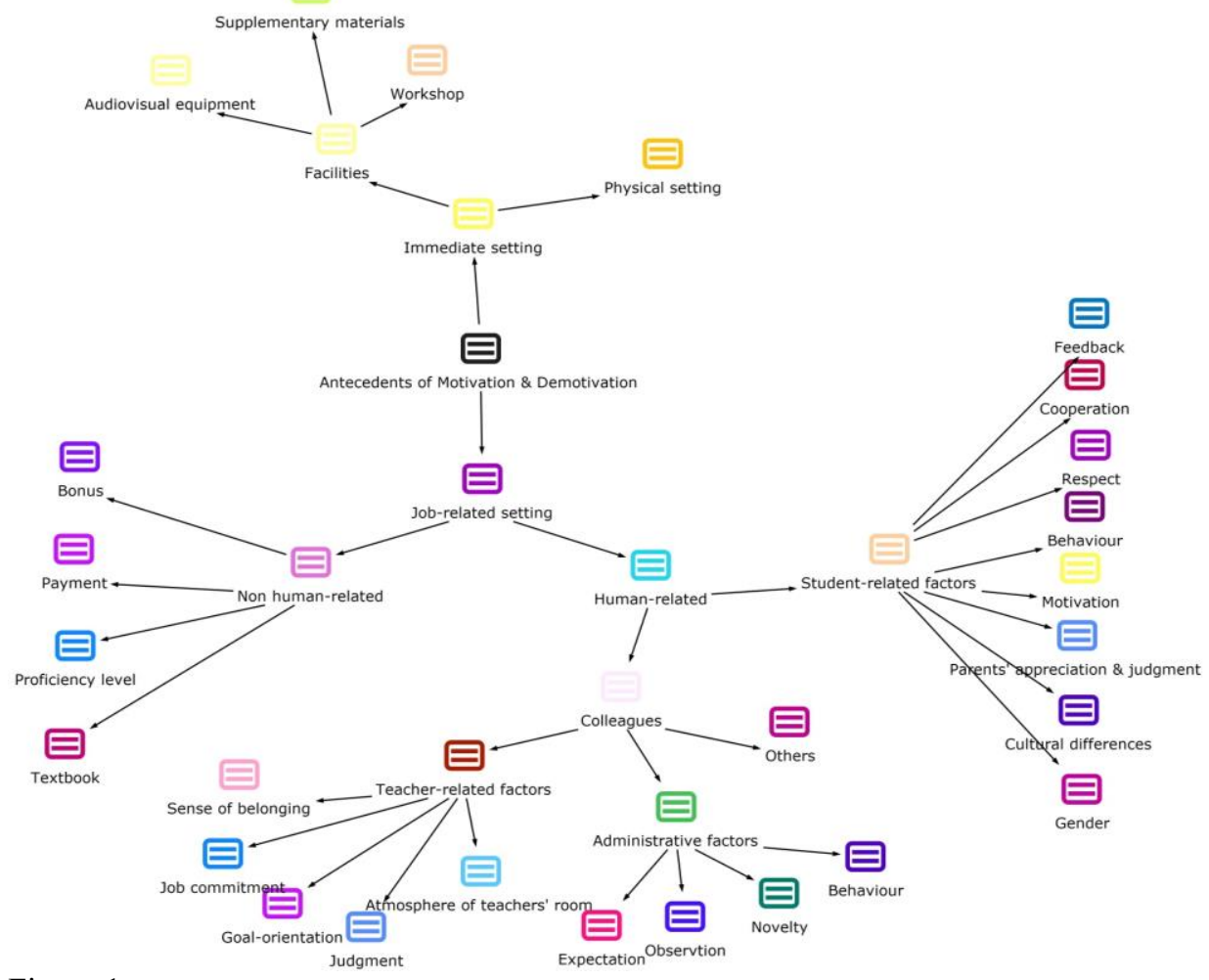

Figure 1

The model of antecedents of motivation and demotivation 
1. Immediate setting refers to the physical aspects of the classroom. Teachers who had suitable immediate setting reported that they were much more motivated comparing to the teachers who experienced teaching in an environment with low quality. Immediate setting encompasses the following categories:

Facilities:

It refers to various amenities in the class such as class materials and audiovisual equipment in the class. This sub factor can lead to motivation if it engages the teacher. For example, a participant declared:

Before coming to this institute, we did not have any access to facilities. But now that I come to the new institute, teachers can have unlimited amount of materials in their classes such as paper, color pencil, audiovisual aids, internet connection, and so on. Also, we can go various workshops including library and gym.

Also, the following example shows how low quality of audiovisual equipment can lead to demotivation. A participant stated:

Having suitable audiovisual equipment is a significant case for me. When I do not have any access to good equipment, I cannot satisfy my students' expectations. Sometimes I want to play music, but without having a good CD player, I feel confused.

Physical setting:

This sub factor focuses on how different aspects of the classroom itself are arranged, including seat arrangement, temperature, and tidiness in class. It can lead to both motivation and demotivation in different situations.

A teacher shared her experience while she experienced a demotivating situation which was the result of low adjustment of the class temperature. She said:

I am currently working in a well-known institute, but the temperature of the classes is not considered appropriately. One of the sessions, the class was cold that my students and I could not concentrate on the lesson. I told them about the problem, but they did not do anything about it; consequently, I felt really dispirited in following the class syllabus assiduously.

2. Job related factors are the second main classification which is divided in 2 general categories: 1) non-human related factors and 2) human-related factors.

2.1. Non-human related factors: The first part which is non-human related factors has 5 sub factors which include textbook, proficiency level, payment, bonus, and sense of belonging.

Textbook:

This factor can lead to teachers' motivation if the content is in line with the teachers' interests and abilities. In addition, it may lead to demotivation if teachers think teachers and students do not have any sense of attachment to it.

Proficiency level:

This refers to proficiency level of students and its congruence or incongruence with their class and with teacher's expectations. A participant raised the issue as follows: 
It has been a long time that I am teaching two particular books, so when the institute does not pay attention to what level I want, I really feel demotivated.

Payment:

This extrinsic factor is a very influential one according to teachers who have been investigated. They reported that their income can affect the degree of their motivation and commitment. A teacher mentioned:

Sometimes I really want to be cool in my classes, but at the end I tell myself that the payment that I receive is not enough. Therefore, I feel demotivated in that particular time when these ideas come to me.

Bonus:

It refers to any promotion teachers get, or it can refer to any praise or acknowledgement, even verbal, they can receive.

Human-related factors: The next part is human related factors referring to any kind of features that can be manipulated by other individuals and alter motivation levels. All its components can affect motivation negatively or positively. Colleagues and students are inseparable part of every English language institution; they are one of the highly prominent factors which can lead to both teachers' motivation and demotivation.

Colleagues:

It includes administrative factors, teacher-related factors, and others.

Administrative factors: it refers to all of the decisions, expectations, rules and regulations imposed by the supervision of the language institution.

Expectation: This is a leading factor in motivation and demotivation. According to teachers, they are concerned about what their managers or supervisors expect them to do. A teacher mentioned that: Sometimes my manager expects me too much, which is higher than my energy or maybe s/he is not aware of my capabilities and capacities.

Observation: Participants were annoyed of too much observation done by supervisors; teachers believed that an outsider cannot decide for their classes as far as some observers prescribe especial method and behavior for teachers to follow. The consequence of plenty of observation sessions leads to demotivation.

Novelty: Rules are inevitable parts of any organization, but teachers reported that inflexible rules for class management prescribed by the institute regulations hamper creativity and innovation. Teachers seek for more novelty, so they reported that they want to have more freedom for novel ideas and approaches.

Teacher-related factor:

Job commitment: It is another factor resulting in teachers' motivation if is high. A teacher stated:

I feel motivated when the institute gives such a responsibility to me which is teaching. Sometimes I am tired, but I do not let it demotivate me because I have to do my job in the best possible manner. 
Goal-orientations: Some teachers publicize the issue that their inner goals can motivate them. Whenever they felt that they achieve what they want, they think that they are highly motivated. A teacher highlighted:

External factors cannot demotivate me. They may cause a little bit of undesirable feeling, but I do not let them to demotivate me. My goals and my achievement motivate me.

Atmosphere of teaching sphere: It refers to the ideas of teachers, or simply what happens in the classroom which can directly motivate or demotivate teachers. A teacher said:

Once I was in an institute where teachers had negative ideas about teaching and education, I was absolutely demotivated. But I am currently working in an institute whose teachers think positively about learners and their learning. They just share their experiences and ideas while they take their break time in the teachers' room; therefore, I am very happy and motivated now.

Judgment: Participants highlighted that some teachers feel free to judge each other. From the interviewees' point of view, it can be considered as a negative aspect which can result in demotivation. A teacher wrote:

Once I asked a question from one of the experienced teachers of the institute. Aside from ignoring the problem, she judged me very badly; therefore, in that time I really felt that I was demotivated.

Sense of belonging: Several teachers believed that they are not in the right place. The teachers who participated in this study mentioned that this sense is the result of others' feeling or ideas which are imposed to the teacher. This factor can lead to motivation if the teachers have a high sense of belonging; while, the low sense of belonging can result in teachers' demotivation.

Others: It refers to other people, except managers and teachers, who work in English language institutes and whose actions and behavior directly have influence on teachers' motivation and demotivation.

Students: It includes all aspects of students, and it is noteworthy to state that this sub factor has the most frequency as shown in Figure 1.

Feedback: It was noted that teachers feel much more motivated if the students give them feedback while they teach or design a task.

Cooperation: It was reported as a noteworthy sub factor for teacher motivation. Teachers mentioned that classes with students who cooperate more and engagement was observed on the part of students, teachers enjoyed higher level of motivation. Also, existence of a negative relationship between cooperation and demotivation is possible.

Respect: Teachers whose students are teenagers or older highlighted that the more respect and admiration students have for their teachers, the more motivated the teachers are.

Behavior: Teachers stated that students' behavior can influence on teacher motivation both positively and negatively meaning that motivation and demotivation can be the result of students' appropriate and inappropriate behavior, respectively. 
Motivation: Nearly most of the teachers felt in their classes that the students' level of motivation can change the degree of teacher motivation. They believed that students' high motivation empower teacher motivation.

Parents' appreciation and judgment: Some teachers were influenced by students' parents. They thought that parents' appreciation leads to teacher motivation and some teachers noted that part of their demotivation is because of parents' negative judgment and ideas.

Cultural differences: Students' cultural differences can be another antecedent that leads to teacher demotivation. According to the collected data, teachers are concerned with cultural differences of their students.

Gender: Students' gender is another sub factor that teachers believe that can motivate or demotivate them in terms of differences of their behavior and actions. A teacher female said

When I had a class with little boys who were difficult to control, I was really demotivated and frustrated.

\section{The model of consequences of teachers' motivation and demotivation}

The consequences of teachers' motivation and demotivation are the next issue. The results showed that they are classified in 3 main categories: 1) physical, 2) behavioural, and 3) attitudinal. Generally, the above classifications have 12 subdivisions which are depicted in Figure 2.

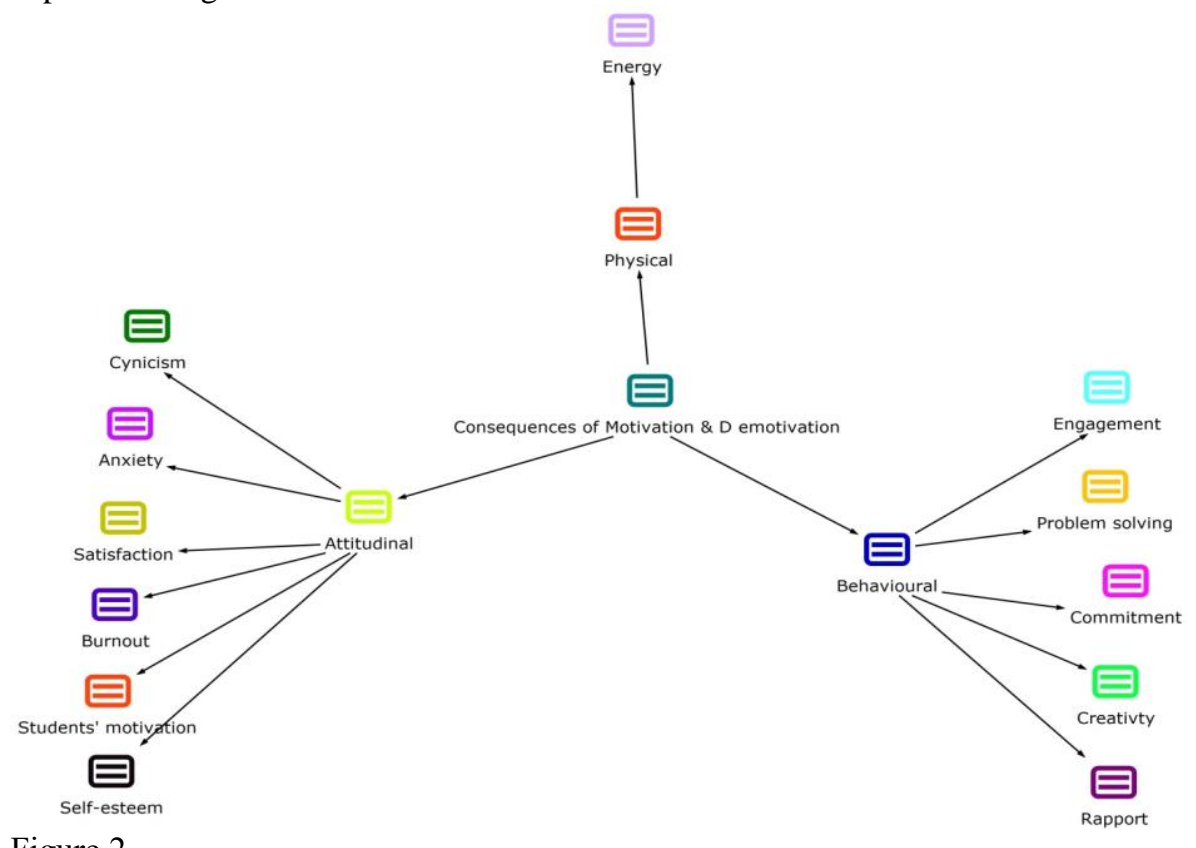

Figure 2

The model of consequences of teachers' motivation and demotivation 
Physical elements: It was shown that teacher motivation and demotivation can directly influence teachers' physical capacities.

Energy depletion or elevation: According to the participants, when a teacher is energetic it is because she is motivated; however, one of consequences of demotivation is lack of teachers' energy in the context of the class.

Attitudinal:

Self-esteem: It refers to the person's overall subjective assessment of his or her own value which is a judgment of oneself as well as an attitude toward the self.

Students' motivation: It is one of the consequences for both motivation and demotivation. It is highlighted that motivated teachers have much more motivated students comparing to the teachers whose motivation is low.

Burnout: As was investigated in 1996, burnout is a psychological syndrome of emotional exhaustion, depression, and reduced personal accomplishment that can occur among individuals who work with other people in some capacity (Maslach, Jackson, \& Leiter, 1996). Some teachers thought that when they teach the same materials over a long period of time, they feel demotivated, and after that they are very tired of teaching and demotivated.

Satisfaction: Teachers with higher motivation have higher satisfaction. Nevertheless, demotivated teachers reported that they are dissatisfied with their teaching profession.

Anxiety: Teachers reported that when they do not feel that they are motivated about their job, they really feel anxious in their profession.

Cynicism: This is one of the consequences of demotivation in teaching. A teacher stated that: when I am demotivated, cynical views come to me. Therefore, I have negative ideas about my job, students, and the institute members.

Behavioral:

Rapport: Teachers reported that their motivation and demotivation can influence on their rapport with their students. As is evident, teachers' motivation can culminate in good rapport with students. However, they said that if they were demotivated, they do not have friendly relationship with their students.

Creativity: Most of the teachers agreed on the issue that their motivation leads to their creativity and they believe that the institute must not block it.

Commitment: Teachers believed that their motivation would influence their willingness of being obligated or emotionally impelled by teaching as well as the relative strength of the teachers' identification with the institution. Teachers reported that they are much more commitment to their profession when they are motivated comparing to the time they are demotivated.

Problem solving: Some teachers agreed that when they are motivated they actively try to find any answer to their questions.

Engagement: Teachers' participation is a very prominent consequence which is the reflection of their motivation. A teacher said: when I am motivated, I really try to 
engage myself in my job, and I try my best to teach very well to my students because they are the sources of my motivation.

\section{DISCUSSION}

As stated earlier, the present study aimed at exploring determinants and consequences of teachers' motivation and motivational detriments among EFL teachers in Iran. The researchers conducted a qualitative study via the triangulation of 3 methods of data collection, including open-ended questions, interviews, and diaries. In so doing, the generated data were codified and classified via MAXQDA 10.

Figure 3 indicated that different professional and non-professional factors lead to teachers' motivation and demotivation. The two main factors are 1) immediate setting and 2) job-related factors. The main category has some sub factors which are shown in the Figure 3.

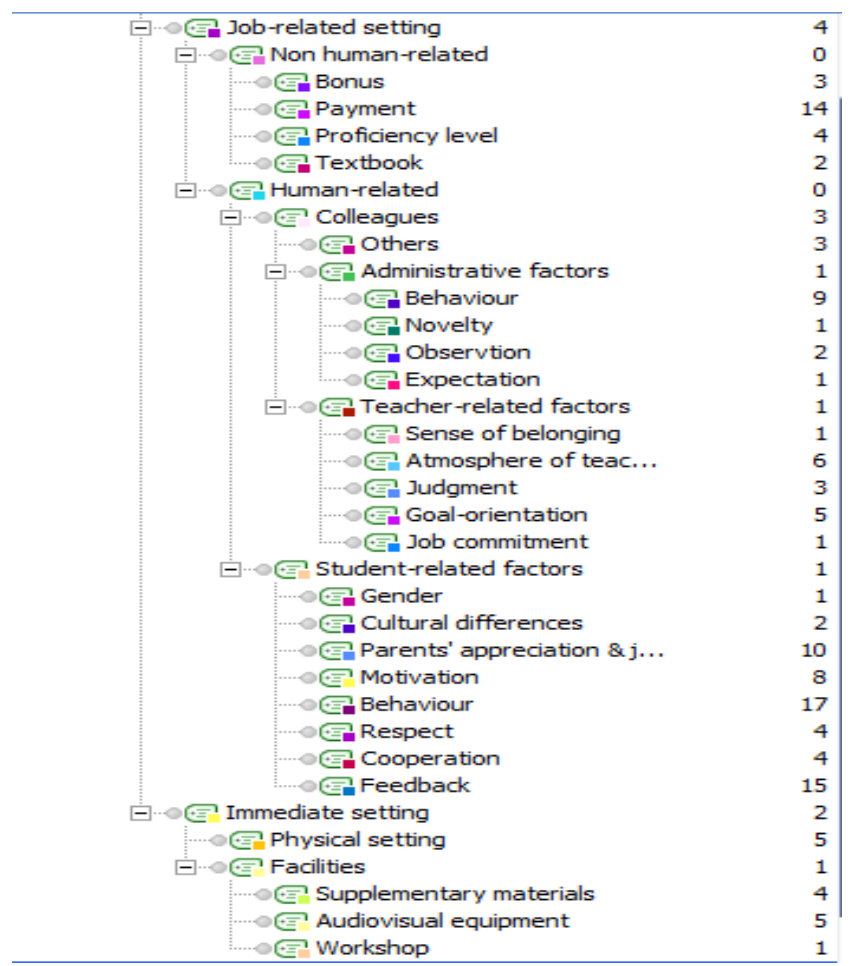

Figure 3

The general scheme and frequency of antecedents of EFL teachers' motivation and demotivation

The results indicated that among the determinants, students-related factors $(n=61)$ had the highest frequency among other sub factors indicating that student-related factors have a great influence in motivating or demotivating teachers. Student-related factors 
comprised 8 sub-factors, including, gender, cultural differences, parents' judgment, motivation, behaviour, respect, cooperation, and feedback. Among student-related factors, student behaviour $(\mathrm{n}=17)$ displayed the highest frequency.

The yielded determinants of teacher motivation and demotivation can be divided into two main categories, i.e., intrinsic and extrinsic motivation (Fernet, Guay, Senécal, \& Austin, 2012).

All in all, the factors can be put into these two groups. As indicated in table 1 all the factors except novelty, goal orientation, and job commitment, and sense of belonging can be considered as extrinsic motivation showing that the most of the influencing antecedents of demotivation and demotivation have an extrinsic rather than intrinsic orientation.

Table 1

Extrinsic vs. Intrinsic Factors

\begin{tabular}{|c|c|c|c|c|}
\hline Factor & Sub factor & & & \\
\hline \multirow[t]{4}{*}{$\begin{array}{l}\text { Immediate } \\
\text { setting }\end{array}$} & \multirow[t]{3}{*}{ facilities } & $\begin{array}{l}\text { Supplementary } \\
\text { material }\end{array}$ & & \\
\hline & & $\begin{array}{l}\text { Audio visual } \\
\text { equipment }\end{array}$ & & \\
\hline & & workshop & & \\
\hline & \multicolumn{2}{|l|}{ Physical setting } & & \\
\hline \multirow{21}{*}{$\begin{array}{l}\text { Job-related } \\
\text { setting }\end{array}$} & \multirow{4}{*}{$\begin{array}{l}\text { Non-human } \\
\text { related setting }\end{array}$} & bonus & & \\
\hline & & payment & & \\
\hline & & Proficiency level & & \\
\hline & & textbook & & \\
\hline & \multirow{8}{*}{$\begin{array}{l}\text { Human related } \\
\text { setting }\end{array}$} & \multirow{8}{*}{$\begin{array}{l}\text { Student related } \\
\text { factors }\end{array}$} & Feedback & \\
\hline & & & Cooperation & \\
\hline & & & Respect & \\
\hline & & & Behavior & \\
\hline & & & Motivation & \\
\hline & & & $\begin{array}{l}\text { Parents' appreciation } \\
\text { and judgment }\end{array}$ & \\
\hline & & & Cultural differences & \\
\hline & & & gender & \\
\hline & & \multirow[t]{9}{*}{ colleagues } & \multirow[t]{5}{*}{$\begin{array}{l}\text { Teacher related } \\
\text { factor }\end{array}$} & $\begin{array}{l}\text { Atmosphere of } \\
\text { teachers' room }\end{array}$ \\
\hline & & & & Judgment \\
\hline & & & & Sense of belonging \\
\hline & & & & Job commitment \\
\hline & & & & Goal orientation \\
\hline & & & \multirow{4}{*}{$\begin{array}{l}\text { Administrative } \\
\text { factors }\end{array}$} & Behavior \\
\hline & & & & Expectation \\
\hline & & & & observation \\
\hline & & & & Novelty \\
\hline
\end{tabular}

Extrinsic

\section{Intrinsic}

International Journal of Instruction, October $2018 \bullet$ Vol.11, No.4 
The results showed that the factors such as inappropriate level, textbook, low payment, colleagues, and students can sturdily lead to teachers' motivation and demotivation which is in line with Ghanizadeh and Erfanian (2017), Falout (2010), Fattash (2013).

Figure 2 shows consequences of teachers' motivation and demotivation. The main categories are: 1) physical, 2) attitudinal, and 3) behavioural. Each category has its own sub categories which are exhibited in Figure 4.

\begin{tabular}{|c|c|}
\hline Code System & 39 \\
\hline- Consequences of Motivation \& D emotivation & 0 \\
\hline$-\oplus$ Behavioural & 0 \\
\hline : & 2 \\
\hline ๔.... Problem solving & 4 \\
\hline C...…… Commitment & 6 \\
\hline Creativty & 5 \\
\hline N...甲 Rapport & 2 \\
\hline$\underset{-1}{-g}$ Attitudinal & 0 \\
\hline 国 Cynicism & 3 \\
\hline 을 Anxiety & 1 \\
\hline ․ㅡㄹ Satisfaction & 2 \\
\hline …… Burnout & 3 \\
\hline Students' motivation & 3 \\
\hline (.... Self-esteem & 2 \\
\hline$\square$ 前Physical & 0 \\
\hline 들 Energy & 6 \\
\hline
\end{tabular}

Figure 4

The general scheme and frequency of EFL teachers' motivation and demotivation consequence

The figure shows that among all sub categories, teachers' commitment got the highest frequency. Table 2 depicts that teachers can react internally or externally while they are motivated or demotivated. So students' motivation and burnout can be considered both intrinsic and extrinsic realizations; moreover, creativity and energy are the external realizations. It is also worth to mention that the rest of the list is intrinsic realizations. Hence, most of the results can be the consequences of both motivation or demotivation including engagement, problem solving, commitment, creativity, self-esteem, students' motivation and energy depletion or elevation meaning that when teachers are motivated they may have high level of the aforementioned factors. Nevertheless, in the case that they are demotivated, the level of the afore-mentioned elements decreases. A few consequences which are all attitudinal such as burnout, anxiety, and cynicism mostly are the effects of demotivation which means that motivated teachers tend to exhibit low level of them. These consequences of demotivation are in accordance with what Falout ( 2010) found. Also, it was found that students' motivation is the result of teachers' motivation which is in harmony with Dörnyei (2005). 
Table 2

Consequences of Motivation and Demotivation Vs. Intrinsic and Extrinsic Nature of them

\begin{tabular}{|c|c|c|c|c|}
\hline Factor & Sub factor & $\begin{array}{l}\text { Consequences of Motivation \& } \\
\text { demotivation }\end{array}$ & Intrinsic & Extrinsic \\
\hline \multirow[t]{4}{*}{ Behavioral } & Engagement & $\checkmark$ & $\checkmark$ & \\
\hline & Problem solving & $\checkmark$ & $\checkmark$ & \\
\hline & Commitment & $\checkmark$ & $\checkmark$ & \\
\hline & Creativity & $\checkmark$ & & $\checkmark$ \\
\hline \multirow[t]{6}{*}{ Attitudinal } & Cynicism & & $\checkmark$ & \\
\hline & Anxiety & & $\checkmark$ & \\
\hline & Satisfaction & $\checkmark$ & $\checkmark$ & \\
\hline & Burnout & & $\checkmark$ & $\checkmark$ \\
\hline & $\begin{array}{l}\text { Students' } \\
\text { motivation }\end{array}$ & $\checkmark$ & $\checkmark$ & $\checkmark$ \\
\hline & Self-esteem & $\checkmark$ & $\checkmark$ & \\
\hline Physical & Energy & $\checkmark$ & & $\checkmark$ \\
\hline
\end{tabular}

\section{CONCLUSION}

Taken together, the results showed that most of the antecedents as well as consequences were external which can be a signal for educators, teacher trainers, and educational policy-makers. They should endeavour to promote the physical settings of teaching and stimulate cooperative and friendly atmosphere. Of course, the internal side of motivation should not be ignored given that intrinsically-derived attributes are more enduring, stable, and controllable. Another issue which can be discussed is that some teachers said that they do not easily become demotivated, and their ideas and goals motivate them; this in turn implies that teachers' initial perceptions and attitudes towards teaching can effectively fashion their subsequent functioning and effectiveness. Additionally, as is evident in the protocols, participants were more aware of the antecedents of their motivation and demotivation in comparison with their consequences showing that teachers are not inclined to find immediate solutions whenever they are demotivated, or take any action to maintain their motivation.

The current study investigated the motivation and demotivation among some university students who worked as teachers, or teachers who worked in an English institute, so some of them may not be highly experienced. Given that some of the participants withdrew the study, the researcher had to continue the investigation with the rest of the participants. Moreover, all of the participants except for the participants of the openended questions were female teachers; so, further assessment must be done on both female and male teachers in order to avoid some gender specific ideas, although a similar study about the antecedents was conducted on male teachers (Ghanizadeh \& Erfanian, 2017), and some overlaps are visible. 


\section{REFERENCES}

Arai, K., (2004). What 'demotivates' language learners?: Qualitative study on demotivational factors and learners' reactions. Bulletin of Toyo Gakuen University 12, 39-47

Aydin, S. (2012). Factors causing demotivation in EFL teaching process : A case study. The Qualitative Report, 17(51), 1-13.

Bandura, A. (1977). Self-efficacy: Toward a unifying theory of behavioral change. Psychological Review, 84(2), 191-215. https://doi.org/10.1037/0033-295X.84.2.191

Bernaus, M., \& Gardner, R. C. (2008). Teacher Motivation Strategies, Student Perceptions, Student Motivation, and English Achievement. The Modern Language Journal, 92(3), 387-401. https://doi.org/10.1111/j.1540-4781.2008.00753.X

Deci, E. L., \& Ryan, R. M. (2000). The "What" and "Why" of goal pursuits: Human needs and the self-determination of behavior. Psychological Inquiry, 11(4), 227-268. https://doi.org/10.1207/S15327965PLI1104_01

Dörnyei, Z. (2005). The psychology of the language learner individual differences in second language acquisition. Lawrence Erlbaum Associates, Inc. https://doi.org/10.1146/annurev.physiol.62.1.135

Dörnyei, Z., \& Ushioda, E. (2011). Teaching and researching motivation (2nd edition). Pearson: Harlow.

Falout, J. (2010). Strategies for teacher motivation. The Language Teacher, 34 (6), 2732.

Fattash, M. M. (2013). Demotivating factors of university ESL teachers. International Journal of Humanities and Social Science, 3(19), 125-132.

Fernet, C., Guay, F., Senécal, C., \& Austin, S. (2012). Predicting intraindividual changes in teacher burnout: The role of perceived school environment and motivational factors. Teaching and Teacher Education, 28(4), 514-525. https://doi.org/10.1016/j.tate.2011.11.013

Fernet, C., Senécal, C., Guay, F., Marsh, H., \& Dowson, M. (2008). The Work Tasks Motivation Scale for Teachers (WTMST). Journal of Career Assessment, 16(2), 256279. https://doi.org/10.1177/1069072707305764

Gardner, R. C. (1985). Social Phsycology and Second Language Learning: the Role of Attitudes and Motivation. Social Phsycology and Second Language Learning. Lawrence Erlbaum Associates.

Ghanizadeh, A., \& Erfanian, J. (2017). Probing the antecedents of Iranian EFL teachers' motivation and demotivation. Journal of English Language and Literature, 7(1), 502508. 
Ghanizadeh, A., \& Rostami, S. (2015). A Dörnyei-inspired study on second language motivation: a cross-comparison analysis in public and private contexts. Psychological Studies, 60 (3), 292-301, DOI: 10.1007/s12646-015-0328-4.

Ghonsooly, B., Hassanzadeh, T., Samavarchi, L., \& Hamedi, M. (2017). A mixedmethods approach to demotivating factors among Iranian EFL learners. Issues in Educational Research, 27(3), 417-434.

Jahedizadeh, S., Ghanizadeh, A., \& Ghonsooly, B. (2016). The role of EFL learners' demotivation, perceptions of classroom activities, and mastery goal in predicting their language achievement and burnout. Asian-Pacific Journal of Second and Foreign Language Education, 1(1), 1-16. https://doi.org/10.1186/s40862-016-0021-8

Maslach, C., Jackson, S. E., \& Leiter, M. (1996). The Maslach Burnout Inventory: Manual. Maslach Burnout Inventory, (January), 191-218.

Meshkat, M., \& Hassani, M. (2012). Demotivating factors in learning english: The case of iran. Procedia - Social and Behavioral Sciences, 31(2011), 745-749. https://doi.org/10.1016/j.sbspro.2011.12.134

Rotter, J. B. (1966). Generalized expectancies for internal versus external control of reinforcement. Psychological Monographs: General and Applied, 80(1), 1-28. https://doi.org/10.1037/h0092976

Royaei, N., \& Ghanizadeh, A. (2016). The Interface between Motivational and Emotional Facets of Organizational Commitment among Instructors at Higher Education. International and Multidisciplinary Journal of Social Sciences, 5(3), 228. https://doi.org/10.17583/rimcis.2016.2139

Sternberg, R. J., \& Dai, D. Y. (2004). Motivation, Emotion and Cognition. Motivation, emotion, and cognition: Integrative perspectives on intellectual functioning and development. https://doi.org/10.4324/9781410610515

Vallerand, R. J. (1997). Toward a hierarchical model of intrinsic and extrinsic motivation. Advances in Experimental Social Psychology, 29, 271-360. https://doi.org/10.1016/S0065-2601(08)60019-2

Yan, H. (2009). Student and teacher de-motivation in SLA. Asian Social Science, 5(1), 109-112. https://doi.org/10.5539/ass.v5n1p109 